TP Periodica Polytechnica Chemical Engineering

\author{
62(2), pp. 224-235, 2018 \\ https://doi.org/10.3311/PPch.10526 \\ Creative Commons Attribution (i)
}

RESEARCH ARTICLE

\section{Quantitative Indicators of Social Sustainability and Determination of Their Interdependencies. Example Analysis for a Wastewater Treatment Plant}

\author{
Tamara Popovic ${ }^{1 *}$, Andrzej Kraslawski ${ }^{1,2}$
}

Received 22 January 2017; accepted after revision 20 March 2017

\begin{abstract}
Social impact as growing concern is becoming an important aspect of the design and operation of wastewater treatment processes. A need has arisen for the development of quantitative indicators of social sustainability. Design and operation of wastewater treatment processes additionally require simple and effective methods to represent and understand the interconnections between the indicators of social sustainability. This paper presents an approach for the development of quantitative social sustainability indicators, and introduces a novel method for defining and visualizing indicator interdependence. It outlines equations for quantitative evaluation of health, safety and security, and comfort. Weighting method of the bipartite network of the relations between the indicators and stakeholders enables clear visualization of the interdependencies of the indicators and facilitates simplification of the set of social sustainability criteria. It creates a basis for reduction of amount of data needed for performing the analysis and reducing the social sustainability assessment's costs.
\end{abstract}

\section{Keywords}

social sustainability, quantitative indicators, wastewater treatment, indicator interdependence, stakeholders

\footnotetext{
${ }^{1}$ Industrial Engineering and Management,

School of Business and Management,

Lappeenranta University of Technology

P.O. Box 20, FI-53851, Finland

${ }^{2}$ Faculty of Process and Environmental Engineering

Technical University of Lodz, Poland

*Corresponding author, e-mail: tamara.popovic@lut.fi
}

\section{Introduction}

Reliable collection and treatment of wastewater contribute greatly to improvement in global health and sanitation, and a reduction in the spread of diseases [1]. Moreover, according to Palme et al. (2005, p. 294) [2] "treatment of wastewater are vital functions in any society". Thus, sustainability - the design and operation of human and industrial systems such that they have minimal negative impact on society, environment and the economy [1] - has become a major goal. It means that successful and sustainable wastewater utility shouldn't only depend on adequate treatment, but it should also consider the impacts of their actions on the society and environment [3]. In that context, the assessment of the possible impacts can help in decision-making and in process of moving toward sustainability. The crucial role in the impacts assessment have sustainability indicators, as they enable measurement of the impacts and can provide information about specific process [4]. Sustainability measures for wastewater treatment processes were studied by many authors, e.g. Balkema et al. (2002) [5], Muga and Mihelcic (2008) [1] and Molinos-Senante et al. (2014) [6]. Balkema et al. (2002) [5] presented an overview of indicators used for comparison of wastewater treatment systems, while Muga and Mihelcic (2008) [1] provided indicators for holistic assessment of the sustainability of wastewater treatment. They came up with an explanation that there should exist method which will enable evaluation of sustainability of wastewater treatment technologies [1]. Molinos-Senante et al. (2014) [6] attended assessment of wastewater treatment plants by using economic, environmental and social indicators. In case of Molinos-Senante et al. (2014) [6], social sustainability was addressed by using qualitative measures for indicators such as odors, noise, visual impact, public acceptance, and complexity.

Even though there are several attempts to address sustainability of wastewater treatment plant (WWTP), the social sustainability remained underexplored and with lack of assessment methods as usual focus was on environmental and economic aspects [7]. That is also stated by the Veldhuizen et al. (2015) [8], where the authors claim that the methods and measurement of social sustainability are not well developed. Nevertheless, 
there are some methods that gained a lot of attention, such as Social Life Cycle Assessment (S-LCA) and Global Reporting Initiative (GRI). For instance, S-LCA selects crucial stakeholders in the life cycle of the product and evaluates the impact of production related processes on the chosen stakeholders [9]. The scope of GRI as monitoring framework is not the full life cycle, but rather it is a framework encompassing three pillars: social, environmental and economic, and development of performance indicators suitable for evaluation of those pillars [10]. GRI indicators are mostly used for monitoring of the performance of organizations, and they are not industry specific, i.e. any organization can use GRI indicators to make an evaluation.

The above-mentioned frameworks have been developed to assess process industry in general, without specifying the type of industry analyzed, i.e. chemical, pharmaceutical, petrochemical etc. The general nature of the frameworks results in certain limitations, for example, the framework may not cover issues specific to a particular process, and thus exist a need for focusing future research on developing process-specific indicators [11]. It looks that the crucial role in developing process-specific indicators have engineers. For instance, Bañares-Alcántara (2010) [12] states that the domain of engineers' competence should be extended from the traditional areas of problem solving and the provision of technological advances to a normative role implicit in policy formulation. Apart from the normative role, "one of the most important tasks of the system engineer is to understand interactions and interdependencies and ways to manage them" claim Naser and Karmani (2012, p.4) [13]. Therefore the need for understanding interactions among social sustainability indicators starts to be evident as it contributes not only to deeper understanding of the phenomena of sustainability but also enables reduction of the costs of its assessment by limiting amount of required data and information.

Consequently this research aims to address previously identified issues by introducing an approach that can be industry-specific by presenting quantitative social sustainability indicators developed specifically for wastewater treatment processes - a major element of water management, and by exploring the interactions among the indicators.

Specifically, this paper will address three aims:

- First, the quantitative social sustainability indicators are proposed for the aspects of health, safety and security, and comfort.

- Second, the proposed indicators are applied to the WWTP.

- Third, novel approach in prioritizing the indicators is proposed based on their interactions.

Finally, the developed indicators should address individual as well as collective perspectives, enabling a comprehensive understanding of the influence of wastewater treatment processes. Further visualization and analysis of interconnections between the indicators and stakeholders should facilitate identification of the indicators of social sustainability having the greatest impact among the whole set of indicators.

The authors such as Balkema et al. (2002) and Muga and Mihelcic (2008) propose social sustainability indicators by using approach where they first estimate the possible impacts of the wastewater treatment process on society and encompassed that with indicators. Similar approach is used in this work, and it will be presented in the following section.

\section{Methodology}

The methodology of this research was following steps presented in Fig. 1, while each step is explained more in details in next paragraphs.

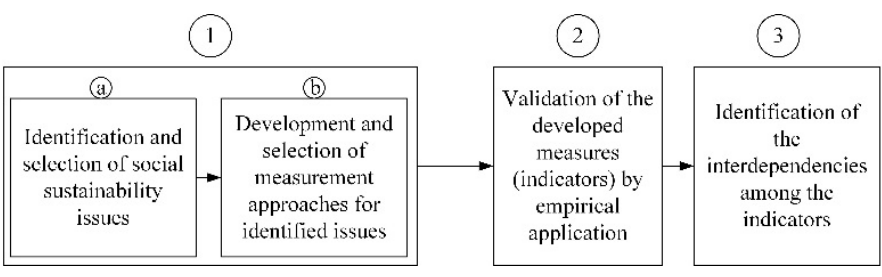

Fig. 1 Overview of the methodology

\section{Step 1}

First step of methodology includes selection and development of sustainability indicators. There is plethora of various methods that can be used for the selection and development of sustainability indicators. However, one of the most commonly used is the issue or theme-based framework [14]. Based on that methodology the indicators are classified according to the various issues that are related to sustainable development [14]. Thus this kind of approach includes identification and selection of sustainability issues (step 1a in Fig. 1) and further development and selection of measurements/indicators (step $1 \mathrm{~b}$ in Fig. 1) for issues identified in step 1a. The advantages of using this method are:

- Ability to link the indicators to policy process,

- Ability to provide clear message to decision-makers,

- Ability to monitor progress in achieving the goals of sustainable development,

- Ability to be flexible, i.e. can be adjusted to new priorities and policy targets [14].

Quality of life can be considered as an essential purpose of the concept of social sustainability [15], and according to Mitchell et al. (1995) [16] quality of life as sustainability goal can be comprised of the issues such as health, security, physical environment (comfort), personal development, community development, and natural resources goods and services [16]. Consequently, selection of issues for this work is primarily focused on those encompassed by quality of life.

The second essential feature enabling incorporation of particular issues into the set defining social sustainability was its quantitative character. In this work quantitative character of the 
issues is reflected in the ability to be attributed and evaluated with indicators on the basis of technical and operational parameters of a wastewater treatment plant. It means that issues were chosen based on their ability to be evaluated in quantitative way.

Based on the two above mentioned criteria - composition of quality of life and quantitative character of the issues; the social issue that is considered is quality of life with subcategories health, safety and security, and comfort. That means that subcategories such as health, safety and security, and comfort have good ability to be evaluated in quantitative way.

Step 1b: The final results will address the impacts that a wastewater treatment plant can have on various aspects of social sustainability and the measures (indicators) developed for each of them. The indicators developed should be:

- Transparent, i.e. they should be understood even by non-experts [1],

- Quantifiable, i.e. it should be possible to calculate them and present them in quantitative way [1],

- Relevant, i.e. they should cover the identified social sustainability issues [1],

- User oriented, i.e. the indicators should be able to match with different users (stakeholders) what further enables better communication of information [17].

\section{Step 2}

Validation of the proposed indicators is considered in the section 4.1 and it is done by applying the developed social sustainability indicators to a wastewater treatment plant. Selection of the case study was based on the capacity of the plant. More than $80 \%$ from among 14,780 investigated facilities have capacity lower than 5 MGD $(18.9 \times 103 \mathrm{~m} 3 /$ day; $18.9 \times 106$ L/day) [18]. Therefore due to the popularity of such facilities, this research focuses on the wastewater treatment plant with capacity $<5$ MGD. Another criterion taken into consideration when choosing the case study was regular reporting. Especially interesting have been wastewater treatment plants with annual reports for the past 5 years. The systematic reports should allow periodic monitoring of social sustainability.

Keeping in mind the above-mentioned factors, North Toronto Wastewater Treatment Plant was chosen as a case study. It is one of the four wastewater treatment plants in City of Toronto, Canada with a capacity of $40 \mathrm{ML} /$ day and it serves a population of about 55,000 [19].

\section{Step 3}

The increased need for reduction of data acquisition costs requires adequate choice of set of indicators for the assessment of sustainability. It means that there should exist a method that will help in choosing the most relevant indicators which can be matched with various stakeholders, i.e. the indicators which can be used by various stakeholders. One of the possible approaches can be bipartite network projection that was initially used in physics and in personal recommendation [20]. The idea relies on the fact that the indicators and stakeholders can be considered as two types of network nodes, wherein the edges are matching stakeholders with the indicators of their interest.

As mentioned above, identification of the stakeholders-indicator match resulted in the creation of the bipartite network. That is actually the network where the nodes are divided into two partitions. The nodes from the different partitions are connected by the edges and nodes from the same partition cannot be connected to each other [21]. As a member of the class of complex networks, bipartite networks can have directed and undirected edges [22]. An example of an undirected bipartite network is presented in Fig. 1a. A method proposed by Zhou et al. (2007) [22] based on studies of allocation dynamics of network-based resources can be used for analysis of this kind of network.
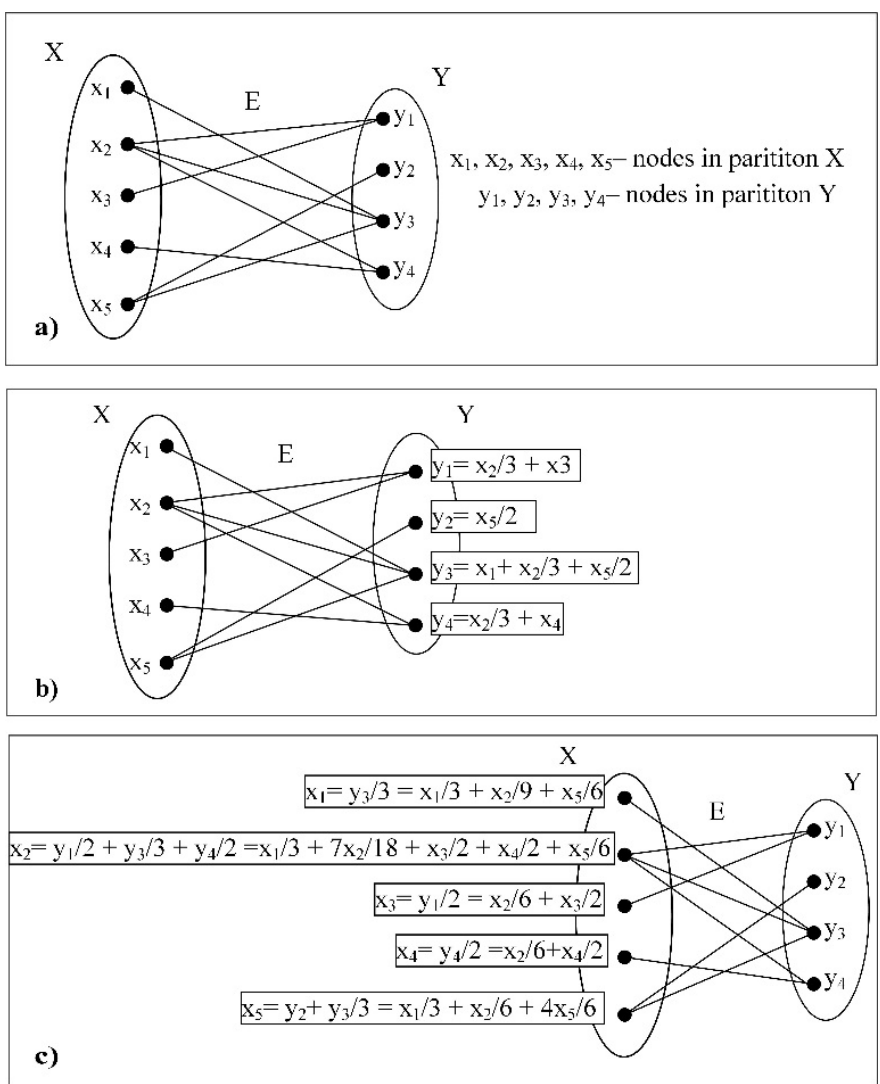

Fig. 2 Undirected bipartite network: a) undirected, unweighted bipartite network; b) first step in the process of weighting $(\mathrm{X} \rightarrow \mathrm{Y})$; c) second step in the process of weighting $(\mathrm{Y} \rightarrow \mathrm{X})$

The scheme of the proposed method is illustrated by the unweighted bipartite network presented in Fig. 2 [22]. The network in Fig. 2a consist of two partitions, $\mathrm{X}$ and $\mathrm{Y}$, and a set of edges $(\mathrm{E})$ between the nodes in partitions $\mathrm{X}$ and $\mathrm{Y}$. The nodes in $\mathrm{X}$ and $\mathrm{Y}$ are $\mathrm{x}_{1}, \mathrm{x}_{2}, \mathrm{x}_{3}, \mathrm{x}_{4}$, and $\mathrm{x}_{5}$ and $\mathrm{y}_{1}, \mathrm{y}_{2}, \mathrm{y}_{3}$, and $\mathrm{y}_{4}$ respectively. The initial resource located on the $i$ th $\mathrm{X}$ node is $f\left(x_{i}\right) \geq 0$.

Before starting the weighting it should be noted that undirected bipartite network (Fig. 2a) is unweighted, that is the resources from $\mathrm{X}$ nodes should be equally distributed to $\mathrm{Y}$ nodes. And vice versa, resources from Y nodes should be 
equally distributed to $\mathrm{X}$ nodes [22]. This statement is permeated through two main steps of the weighting method:

1. All resources in $X$ are directed to $Y$ (Fig. 2b), where the resource located on the $y_{l}$ node has value:

$$
f\left(y_{l}\right)=\sum_{i=1}^{n} \frac{a_{i l} f\left(x_{i}\right)}{k\left(x_{i}\right)}
$$

Where:

- $k\left(x_{i}\right)$ is degree of $x_{i}$

- $a_{i l}$ is a $n \times m$ adjacent matrix:

$$
a_{i l}=\left\{\begin{array}{cc}
1, & x_{i} y_{l} \in E, \\
0, & \text { otherwise. }
\end{array}\right.
$$

2. All resources are directed back to $X$ (Fig. 2c), where the final resource located on the $x_{i}$ node has value:

$$
f^{\prime}\left(x_{i}\right)=\sum_{l=1}^{m} a_{i l} f\left(y_{l}\right) / k\left(y_{l}\right)=\sum_{l=1}^{m} \frac{a_{i l}}{k\left(y_{l}\right)} \sum_{j=1}^{n} \frac{a_{j l} f\left(x_{j}\right)}{k\left(x_{j}\right)}
$$

The weighting can be presented as:

$$
f^{\prime}\left(x_{i}\right)=\sum_{j=1}^{n} w_{i j} f\left(x_{j}\right)
$$

Where:

$$
w_{i j}=\frac{1}{k\left(x_{j}\right)} \sum_{l=1}^{m} \frac{a_{i l} a_{j l}}{k\left(y_{l}\right)}
$$

The matrix $\left(W=\left\{w_{i j}\right\}_{n \times n}\right)$ is obtained after performing the above steps, Table 1. The matrix represents the weighted $\mathrm{X}$ projection [22].

Table 1 Weighted X projection of the bipartite network

\begin{tabular}{llllll}
\hline & $\mathrm{x}_{1}$ & $\mathrm{x}_{2}$ & $\mathrm{x}_{3}$ & $\mathrm{x}_{4}$ & $\mathrm{x}_{5}$ \\
\hline $\mathrm{x}_{1}$ & $\mathbf{1 / 3}$ & $1 / 9$ & 0 & 0 & $1 / 6$ \\
$\mathrm{x}_{2}$ & $1 / 3$ & $\mathbf{7 / 1 8}$ & $1 / 2$ & $1 / 2$ & $1 / 6$ \\
$\mathrm{x}_{3}$ & 0 & $1 / 6$ & $\mathbf{1 / 2}$ & $1 / 2$ & $1 / 6$ \\
$\mathrm{x}_{4}$ & 0 & $1 / 6$ & 0 & $\mathbf{1 / 2}$ & 0 \\
$\mathrm{x}_{5}$ & $1 / 3$ & $1 / 6$ & 0 & 0 & $\mathbf{4 / 6}$ \\
\hline
\end{tabular}

Evaluation of the structural dependence among the $\mathrm{X}$ nodes (i.e. pair-wise dependence) is performed after obtaining the weights of the $\mathrm{X}$ projection. Structural dependence is determined by Eq. (6):

$$
D_{i j}=\frac{w_{j i}}{w_{i i}}
$$

Where:

$D_{i j}$ - dependence of $i$ (X node) on $j$ (X node) as a result of their ties with $\mathrm{Y}$ node

$w_{j i}$ - number of ties that $\mathrm{X}$ node $(i)$ shares with another $\mathrm{X}$ node (j),

$w_{i i}$-amount of resources that return to the $\mathrm{X}$ node $(i)$ at the end of the flow-based transformation (bold values in Table 1).
The value 0 indicates complete independence and the value 1 complete dependence [23].

Values of pair-wise dependency are presented in Table 2. The information given in Table 2 can be used for node-level assessment. This means that a score, i.e. an impact value for each indicator, can be determined. The impact value is calculated by summation of the columns of the pair-wise dependency (Table 2) and by dividing the obtained value by $n-1$, where $n$ is the number of $\mathrm{X}$ nodes:

$$
D_{c}=\frac{\sum_{j \neq i} \frac{w_{j i}}{w_{i i}}}{(n-1)}
$$

Where:

- $D_{c}$ is dependency centrality

- $w_{j i}$ is weight of a tie from X node $\mathrm{j}$ to $\mathrm{X}$ node $i$

- $w_{i i}$ is weight of X node $i$ 's self-loop

- $n$ is total number of X nodes in the network [23].

Table 2 Results of pair-wise dependency and node-level assessment (score values)

\begin{tabular}{llllll}
\hline & $\mathrm{x}_{1}$ & $\mathrm{x}_{2}$ & $\mathrm{x}_{3}$ & $\mathrm{x}_{4}$ & $\mathrm{x}_{5}$ \\
\hline $\mathrm{x}_{1}$ & 0 & 0.28 & 0 & 0 & 0.25 \\
$\mathrm{x}_{2}$ & 1 & 0 & 1 & 1 & 0.25 \\
$\mathrm{x}_{3}$ & 0 & 0.43 & 0 & 0 & 0 \\
$\mathrm{x}_{4}$ & 0 & 0.43 & 0 & 0 & 0 \\
$\mathrm{x}_{5}$ & 1 & 0.43 & 0 & 0 & 0 \\
\hline Score & 0.5 & 0.39 & 0.25 & 0.25 & 0.125 \\
\hline
\end{tabular}

The information obtained by calculating the dependency centrality enables identification of key actors from the bipartite data [23]. Node $x_{1}$ is considered to have the greatest impact and node $\mathrm{x}_{5}$ the lowest impact.

\section{Social sustainability indicators}

This section presents the social sustainability indicators developed for the specific aspects of quality of life.

Quality of life. Quality of life is a broad concept that includes the subcategories of health, safety and security, and comfort. Therefore, the indicators developed for quality of life assessment are allocated to those three subcategories.

Health. Various activities in a wastewater treatment plant, such as control of pollutants present in influents and effluents, detection of chemicals, release of volatile organic compounds (VOC), toxic air contaminants and disinfection by-products, etc., can have an impact on human health. Therefore, assessment of health issues in wastewater management is of great importance [24]. Accordingly, health indicators were developed on the basis of technical and operational parameters of the wastewater treatment plant: pollution, volume of wastewater, cleaning properties, sewer connections, etc. The indicators of the health aspect are following: 
H1 Cleaning efficiency [25] - Cleaning efficiency evaluated as a ratio of the value of basic parameters (suspended solids, carbonaceous biological oxygen demand, total phosphorus, etc.) at the end of the process (in effluent) and the value of effluent basic parameters regulated by law:

$$
H 1=\frac{c_{\text {end }}}{c_{\max }}
$$

Where $H 1$ is cleaning efficiency indicator; $c_{\text {end }}$ is concentration of pollutants at the end of the process; $c_{\max }$ is maximum allowed concentration of pollutants.

Preferred value for this indicator is $<1$.

H2 Time lost - Number of hours lost per employee per year related to diseases and injuries that can occur during the performance of a particular job:

$$
H 2=H_{\text {lost }} / E_{\text {tot }}
$$

Where $H 2$ is time lost indicator; $H_{\text {lost }}$ is total number of hours lost per year; $E_{t o t}$ is total number of employees.

Employees/operators in a wastewater treatment plant are exposed to various hazardous substances, such as vapors, odors, heat, dust, noise from motors, pumps and engines, etc. [26], thus the target value for this indicator is 0 .

H3 Vision [25] - Percentage of annual plant budget devoted to vision. Vision presents the intention of the wastewater treatment plant to achieve certain cleaning properties (e.g. reduce concentration of pollutants in effluent, improve sludge treatment, etc.):

$$
H 3=\frac{I_{v i s}}{B_{t o t}} \times 100
$$

Where $H 3$ is vision indicator; $I_{v i s}$ is investments for vision; $B_{\text {tot }}$ is total annual plant budget.

Investments in vision can improve wastewater treatment plant properties, thus reducing negative health impact on society. Target value for this indicator is as high as possible, but maximum $100 \%$.

H4 Local affairs - Total number of audits per year that check and confirm the relevance and accuracy of wastewater treatment plant measurement:

$$
H 4=\frac{N A_{\text {tot }}}{\text { year }}
$$

Where $H 4$ is local affairs indicator; $N A_{\text {tot }}$ is total number of audits.

Performing audits can help companies to meet their obligations to respect laws that protect public health [27], thus target value for this indicator should be as high as possible, with a maximum regulated by law.

H5 Public finances - Percentage of annual local budget devoted to audits:

$$
H 5=\frac{B_{\text {aud }}}{L B_{\text {tot }}} \times 100
$$

Where $H 5$ is public finances indicator; $B_{\text {aud }}$ is amount of money devoted for wastewater treatment audits; $L B_{\text {tot }}$ is annual local budget for all types of audits.

The indicator shows the willingness of local institutions to make audits and thus ensure protection of public health.

H6 Sewer network [25] - Percentage of households/population connected to wastewater treatment:

$$
H 6=\frac{H H_{c o n}}{H H_{t o t}} \times 100
$$

Where $\mathrm{H} 6$ is sewer network indicator; $\mathrm{HH}_{\text {con }}$ is number of households/residents connected to the wastewater treatment; $\mathrm{HH}_{\text {tot }}$ is total number of households/residents in community.

Lack of connections to public wastewater treatment can lead to waterborne diseases. Target value for this indicator is $100 \%$.

H7 Continuous disposal - Ratio of volume of wastewater and plant capacity:

$$
H 7=\frac{V_{w w}}{C a p}
$$

Where $H 7$ is continuous disposal indicator; $V_{w w}$ is volume of wastewater; Cap is plant capacity.

The indicator shows the capability of the wastewater treatment plant to accept and treat all wastewater. Preferred level for this indicator is $<1$.

H8 Problem handling - Ratio of the number of periodic analysis and maintenance of equipment and the number of analysis and maintenance required by the framework of the management plan:

$$
H 8=\frac{H A}{H A_{\text {fram }}}
$$

Where $H 8$ is problem handling indicator; $H A$ is the number of periodic analysis and equipment maintenance; $H A_{\text {fram }}$ is the number of analysis and equipment maintenance required by the framework of the management plan.

The existing hazards can affect the health of employees and in a broader sense affect the health of society. Therefore, proper monitoring of hazards and their periodic analysis can reduce negative impacts on public health. The target value for this indicator is 1 .

Safety and security. Safety and security can be compromised by accidents, pollution, hazardous situations, etc. [28]. Good training, appropriate handling of plant operations and adequate monitoring are required to ensure safety and security. Consequently, indicators of safety and security were developed to evaluate operational aspects that may compromise safety and security and to audit mitigation actions: 
SS1 Employee training [25] - Hours of training performed per employee per year:

$$
S S 1=\frac{T_{t o t}}{E_{t o t}}
$$

Where SS1 is employee training indicator; $T_{\text {tot }}$ is total hours of training per year; $E_{\text {tot }}$ is total number of employees.

Employee training helps to workers to obtain required skills and thus ensure safe and secure performance of job. Target value for this indicator is as high as possible, with a maximum regulated by company's strategy.

SS2 National and supranational impacts - Ratio of the concentration of hazardous substances of major international concern (e.g. mercury, persistent organic pollutants - POPs) in effluent to the maximum allowed concentration of priority hazardous substances in effluent:

$$
S S 2=\frac{c_{h p}}{c_{h p, \max }}
$$

Where SS2 is national and supranational impacts indicator; $c_{h p}$ is concentration of hazardous substances of major international concern in effluent; $c_{h p \text {, max }}$ is maximum allowed concentration of hazardous substances of major international concern in effluent.

Agenda 21 notes that the requirements of international law should support and promote sustainable development, such as regular sampling and evaluation of polluting components [29]. Therefore, compliance of results with international laws can show how the wastewater treatment plant is supporting sustainable development. The target value for this indicator is $\leq 1$.

SS3 Monitoring - Ratio between the number of effluent samplings per month and number of effluent sampling per month required by law of wastewater treatment policy:

$$
S S 3=\frac{S}{S_{\text {law }}}
$$

Where $S S 3$ is monitoring indicator; $S$ is number of sampling per month; $S_{\text {law }}$ is number of sampling per month required by law or policy.

Safety and security can be ensured by regular monitoring of pollutant concentrations in water effluents. Sampling is usually done according to a sampling protocol and sampling plan giving the number of sampling locations, number and type of samples, and time intervals between sampling [24]. Target value for this indicator is 1 .

SS4 Safety improvement [25] - Ratio between successful safety improvements projects (stated goals achieved) in a certain time period and the total number of projects in the wastewater treatment plant:

$$
S S 4=\frac{P_{s u c}}{P_{t o t}}
$$

Where $S S 4$ is safety improvement indicator; $P_{\text {suc }}$ is number of successful projects; $P_{\text {tot }}$ is total number of projects.

Fulfilling the stated goals of project concerning the safety improvements in wastewater treatment plants show commitment for ensuring safer environment, thus target value for this indicator is 1 .

SS5 Employability - Percentage of local employees:

$$
S S 5=\frac{E_{l o c}}{E_{t o t}} \times 100
$$

Where SS5 is employability indicator; $E_{l o c}$ is number of local employees; $E_{\text {tot }}$ is total number of employees.

The indicator shows the financial security to local residents provided by the wastewater treatment plant. Target value for this indicator is $100 \%$.

SS6 Labor union - Percentage of employees who are members of a labor union:

$$
S S 6=\frac{E_{l u}}{E_{t o t}} \times 100
$$

Where SS6 is labor union indicator; $E_{l u}$ is number of employees joined to labor union; $E_{\text {tot }}$ is total number of employees.

The aim of a labor union is to protect and promote the interests of employees, such as benefits, job security, and safety issues [30]. Thus the target value for this indicator is $100 \%$.

Comfort. Discomfort can be caused by noise, malodors, pollution, etc. [31]. Malodors, noise, etc. are serious concerns to the public, and they can become harmful following a difference in the distance between the plant and households or as a result of improper operation of the plant. The indicators developed for this subcategory evaluate possible violations of comfort:

C1 Environmental protection - Average levels of noise, malodors, and light and air pollution:

$$
C 1=\sum_{n=1}^{N} \frac{L_{n}}{N}
$$

Where $C 1$ is environmental protection indicator; $L$ is level of noise, malodors, light or air pollution and $N$ is total number of measurements made for noise, malodors, and light or air pollution.

High levels of noise, malodors, and light or air pollution can cause discomfort, therefore target value for this indicator is as low as possible, with minimum 0 .

C2 Operational discipline - Yearly average measured levels of noise, malodors, and light and air pollution:

$$
C 2=\frac{\sum_{n=1}^{N} L_{\text {meas }, \bar{n}}}{N}
$$

Where $C 2$ is operational discipline indicator; $L_{\text {meas }}$ is measured levels of noise, smell, light pollution or air pollution; $n$ is number of times of measuring noise, smell, light or air pollution; $N$ is total number of times of measuring noise, smell, light or air pollution in year. 
Exceeding the legal limits of levels of noise, malodors, air and light pollution, etc. can have a negative impact on comfort. Calculation of the degree to which limits are exceeded is significant for evaluation of the effect of the wastewater treatment plant on comfort. Target value for this indicator is $\leq 1$.

C3 Improvement initiatives - Percentage of annual budget invested in new technology to improve working conditions (reduce noise, air pollution, work-related injuries, etc.):

$$
C 3=\frac{I_{t e c}}{B_{t o t}} \times 100
$$

Where $C 3$ is improvement initiatives indicator; $I_{\text {tec }}(€)$ is investments in improving technology; $B_{\text {tot }}$ is total annual budget.

Hazardous factors existing in the working environment and having unfavorable impact on personnel can be noise generated by machinery, various gases, inadequate light, etc. These impacts can be reduced by investing in new modern technologies, thus evaluation of this indicator can be done by considering the level of investments. The target value for this indicator is as high as possible, with a maximum regulated by company's strategy.

C4 Public perception - Number of complaints from local residents related to noise, malodors, light pollution, etc.:

$$
C 4=\sum_{d}^{D} \operatorname{Compl}_{d}
$$

Where $C 4$ is public perception indicator; Compl is number of complaints per year for all types of discomforts $D$ (noise, malodors, light pollution, etc.).

Increased awareness leads to stronger personal perception of environmental issues [32]. So the number of complaints can illustrate the extent to which the wastewater treatment plant is moving toward social sustainability. Target value for this indicator is 0 complaints per year.

C5 Onerousness [25] - Length $(\mathrm{km})$ of public sewer pipes maintained, inspected or replaced per year:

$$
C 5=\sum_{n=1}^{N} l_{s p, n}
$$

Where $C 5$ is onerousness indicator; $l_{s p}(\mathrm{~m})$ is length of sewer pipes maintained, inspected or replaced per year in total number of locations $N$.

Regular maintenance, inspections or replacements of sewer pipes can reduce the risk of deterioration, blockage or collapses of sewer system [33]. Target value for this indicator is that all pipes that require maintenance, inspection or replacement are managed.

C6 Shock loads- Ratio of the size of storage basin and volume of the shock loads:

$$
C 6=\frac{S B}{S L_{v}}
$$

Where $C 6$ is shock loads indicator; $S B$ is size of storage basin $\left(\mathrm{m}^{3}\right) ; S L_{v}$ is volume of the shock loads.

Target value for this indicator is $<1$.

C7 Scope of sludge treatment [25] - Percentage of sludge that is treated in different ways, such as use in agriculture, thermal disposal, landfills, etc.:

$$
C 7=\frac{S_{t r}}{S_{t o t}} \times 100
$$

Where $C 7$ is scope of sludge treatment indicator; $S_{t r}$ is amount of treated sludge; $S_{t o t}$ is total amount of sludge.

Treatment of sludge can be beneficial in various ways, such as improving agricultural productivity. Desired levels for this indicator are as high as possible, with maximum 100\%.

C8 Location - Ratio between the distance of the wastewater treatment plant from the community and the distance regulated by law:

$$
C 8=\frac{D}{D_{\text {law }}}
$$

Where $C 8$ is location indicator; $D$ is distance of the wastewater treatment plant from community; $D_{\text {law }}$ is distance required by law.

Values higher than 1 can indicate possible increase in nuisance problems (e.g. odors, noise, etc.) [27]. Thus target value for this indicator is $\leq 1$.

\section{Results and discussion}

The results are divided in two parts. First part (Section 4.1) includes validation of proposed indicators, which is calculation of the indicators by using a data from annual reports of North Toronto Wastewater Treatment Plant. Whereas the second part (Section 4.2) includes weighting the indicators with approach of bipartite network projection.

\subsection{Application of the developed social sustainability indicators to a wastewater treatment plant}

It was mentioned that the data for the validation and calculation of indicators is obtained from the annual reports of the North Toronto Wastewater Treatment Plant. The period of 5 years (2010-2014) is considered in order to illustrate the usage of the indicators for periodical monitoring. The values of indicators for the period of 2010-2014 are shown in Table 3. The bold numbers indicate best result for a chosen period, while cells without values indicate lack of data. For indicators such as $\mathrm{H} 8, \mathrm{SS} 3$, and SS5 it was not possible to obtain all required data, so only total number of equipment maintenance events (for H8), total number of samplings (for SS3), and total number of employees (for SS5) are shown.

The obtained results show improvement of the indicators $\mathrm{H} 1$, H2, H7, H8, SS2, and SS3 in 2014. However, the indicators H3, C3 and C4 attained better values before 2014. Based on that it 
can be observed that the proposed indicators can be used for periodical monitoring of the social sustainability. The indicators can point out the aspects of sustainability needing an improvements.

The lack of data can indicate that the collection costs are high and therefore the needed information is omitted in the report. Consequently, the following section will try to address this issue by proposing the method which can weight indicators and enable their prioritization, thus reducing the number of indicators that should be evaluated. Further, it can lead to the reduction of the data needed for calculation of the indicators and therefore to the reduction of the cost of data collection. The weighting of the indicators is based on the 'indicators-stakeholder' relationship.

Table 3 Overall results of indicators' calculation for 5-years period

\begin{tabular}{|c|c|c|c|c|c|c|}
\hline & & $2010^{\mathrm{a}}$ & $2011^{\mathrm{b}}$ & $2012^{\mathrm{c}}$ & $2013^{\mathrm{d}}$ & $2014^{e}$ \\
\hline \multirow{3}{*}{ H1 } & $\mathrm{SS}(\mathrm{mg} / \mathrm{l})$ & 0.29 & 0.32 & 0.25 & 0.19 & 0.16 \\
\hline & CBOD5 (mg/l) & 0.09 & 0.16 & 0.10 & 0.11 & 0.09 \\
\hline & $\mathrm{TP}(\mathrm{mg} / \mathrm{l})$ & 0.6 & 0.5 & 0.5 & 0.4 & 0.4 \\
\hline $\mathrm{H} 2$ & & 211 & 11 & $\mathbf{0}$ & 1.45 & $\mathbf{0}$ \\
\hline H3 & & 0.20 & 1.44 & 1.24 & 1.22 & 0.01 \\
\hline $\mathrm{H} 4$ & & - & - & - & - & - \\
\hline H5 & & - & - & - & - & - \\
\hline H6 & & 2.10 & 2.10 & 2.10 & 2.10 & 2.10 \\
\hline $\mathrm{H} 7$ & & 0.90 & 0.75 & 0.6575 & 0.61 & 0.58 \\
\hline $\mathrm{H} 8$ & & 4 & 6 & 5 & 10 & 14 \\
\hline SS1 & & 40 & 40 & 40 & 40 & 40 \\
\hline $\mathrm{SS} 2$ & $\mathrm{Hg}$ & 0.29 & 0.30 & 0.27 & 0.27 & 0.15 \\
\hline SS3 & & 2880 & 2708 & 2568 & 2952 & 2967 \\
\hline SS4 & & 1 & 1 & 1 & 1 & 1 \\
\hline SS5 & & 12 & 12 & 12 & 11 & 11 \\
\hline SS6 & & - & - & - & - & - \\
\hline $\mathrm{C} 1$ & & - & - & - & - & - \\
\hline $\mathrm{C} 2$ & & - & - & - & - & - \\
\hline C3 & & 5.56 & 3.23 & 0.78 & 1.22 & 2.79 \\
\hline $\mathrm{C} 4$ & & 0 & 0 & 0 & o & 1 \\
\hline $\mathrm{C} 5$ & & - & - & - & - & - \\
\hline C6 & & 0 & 0 & 0 & 0 & 0 \\
\hline C7 & & 100 & 100 & 100 & 100 & 100 \\
\hline $\mathrm{C} 8$ & & - & - & - & - & - \\
\hline
\end{tabular}

aData from [19]; b Data from [34]; ' Data from [35]; ${ }^{\mathrm{d}}$ Data from [36]; ${ }^{\mathrm{e}} \mathrm{Data}$ from [37]

\subsection{Weighting of bipartite network}

As mentioned above, the weighting of the indicators is based on their relation with stakeholders. Namely it was considered that apart from the classification of the indicators according to the social sustainability aspects, one can also identify two types of indicators: internal and external. The internal indicators are of high interest to internal stakeholders (e.g. company's top management, employees), while external indicators are of interest to external stakeholders (e.g. local residents, NGOs, local authority, central authority). Nevertheless there are some indicators that are of interest for both groups of stakeholders, thus for creating 'indicator-stakeholders' network first were identified stakeholders:

1 - Local residents

2 - NGOs (non-governmental organizations)

3 - Company (top management)

4 - Employees

5 - Local authority

6 - Central authority.

Further identification of the 'indicator-stakeholder' relationship was based on identified issues that are of significant interest for various stakeholders [7, 38]:

- Local residents usually have interest in the services provided by wastewater treatment plant, and having impact on their life such as the degree of wastewater cleaning. This issue could be closely related to efficiency of the process, cleaning properties and factors affecting the efficiency of the process.

- Typically, NGOs have interest in the issues related to broader social issues, e.g. worker rights, etc.

- The company, and more specifically its management, has strong interest in the social issues having a direct impact on the quality of the plant operation, e.g. working conditions, health and safety aspects.

- The employees have interest in health and safety issues, training, working conditions, etc.

- The local authorities have interest in the issues related to the legal aspects of operation of the plant on their territory e.g. law requirements related to use of land or acceptable level of emissions.

- The central authorities usually take care of the aspects which could provoke the conflicts between the stakeholders e.g. issues related to ensuring the acceptable by the population quality of life.

The matrix that resulted from the analysis of the interests of the particular groups of the stakeholders is presented in Table 4. It shows the typical indicators for a given group of stakeholders while the network corresponding to the matrix presented in Table 4 is given in Fig. 3.

The resulting network was weighted by using the approach proposed by Zhou et al. (2007) [22] and presented in the methodology part of this paper (Section 2).

The social sustainability indicators are considered as $\mathrm{X}$ nodes and stakeholders as $\mathrm{Y}$ nodes. The final result (matrix $\left.W=\left\{w_{i j}\right\}_{n \times n}\right)$, presented in Appendixes section in Table A1, is obtained after applying Eq. (1), (2), (3), (4) and (5) (in the first and second step).Ascertaining values for the matrix $W=\left\{w_{i j}\right\}_{n \times n}$ 
Table 4 Matrix of relationship between social sustainability indicators and stakeholders

\begin{tabular}{|c|c|c|c|c|c|c|}
\hline & 1 & 2 & 3 & 4 & 5 & 6 \\
\hline H1 & $X$ & & $X$ & & $X$ & $X$ \\
\hline $\mathrm{H} 2$ & & & $X$ & $X$ & $X$ & $X$ \\
\hline H3 & $X$ & $X$ & $X$ & & & \\
\hline H4 & & & & & $X$ & X \\
\hline H5 & & & & & $X$ & $\mathrm{X}$ \\
\hline H6 & & & $X$ & & & \\
\hline $\mathrm{H} 7$ & & & $X$ & & & \\
\hline H8 & $X$ & $\mathrm{X}$ & $X$ & $X$ & & \\
\hline $\mathrm{SS} 1$ & $X$ & & $X$ & $X$ & & \\
\hline $\mathrm{SS} 2$ & $X$ & & & & $X$ & $\mathrm{X}$ \\
\hline $\mathrm{SS} 3$ & & & $X$ & & $X$ & $\mathrm{X}$ \\
\hline SS4 & & & $X$ & & & \\
\hline SS5 & $X$ & $X$ & & $X$ & $X$ & \\
\hline SS6 & & & $X$ & $X$ & & \\
\hline $\mathrm{C} 1$ & $X$ & $\mathrm{X}$ & $X$ & & & \\
\hline $\mathrm{C} 2$ & $X$ & & $X$ & & & \\
\hline C3 & & & $X$ & & $X$ & X \\
\hline $\mathrm{C} 4$ & $X$ & & $X$ & & & \\
\hline C5 & $X$ & & $X$ & & $X$ & \\
\hline C6 & & & $X$ & & & \\
\hline $\mathrm{C} 7$ & $X$ & & $X$ & & & \\
\hline C8 & $X$ & & $X$ & & $X$ & $X$ \\
\hline
\end{tabular}

is followed by calculating the structural dependence between the social sustainability indicators. Equation (6) is used for this purpose, where the values marked in green in Table A1 present the self-loop values $\left(w_{i j}\right)$. The self-loop value $\left(w_{i j}\right)$ means a number of resources that return to the indicator at the end of the flow-based transformation. The final result for the structural dependence is shown in Table A2, where the value of one cell represents the level of structural dependency of the indicator denoting row on indicator denoting column. Thus, for example, indicator H1 has 0.77 structural dependency on $\mathrm{H} 2,0.38$ on $\mathrm{H} 3,0.62$ on $\mathrm{H} 4,0.62$ on $\mathrm{H} 5,0.15$ on H6, etc. Values closer to 1 show stronger dependency and values closer to 0 indicate greater independence.

The result of pair-wise dependencies, Table A2, is next used for calculation of the scores of the indicators (Eq. (7)), i.e. determination of the indicator with the greatest impact on the other indicators. The obtained results are presented in Table A2 and marked with orange color. Hence it can be seen that indicators $\mathrm{H} 1, \mathrm{H} 2$ and $\mathrm{C} 8$ have the greatest impact, while $\mathrm{H} 4, \mathrm{H} 5$, H6, SS4 and C6 are those with the lowest impact. Therefore prioritization of the indicators according to their impact (from the greatest to the lowest impact) is as follows: $\mathrm{H} 1, \mathrm{C} 8, \mathrm{H} 2$, H8, C5, SS3, C3, SS1, H3, C1, SS5, C7, C4, C2, SS2, SS6, H7, SS4, H6, C6, H5, H4.

The objective of this prioritization is not directly linked to the importance of particular indicator. Rather it is related to

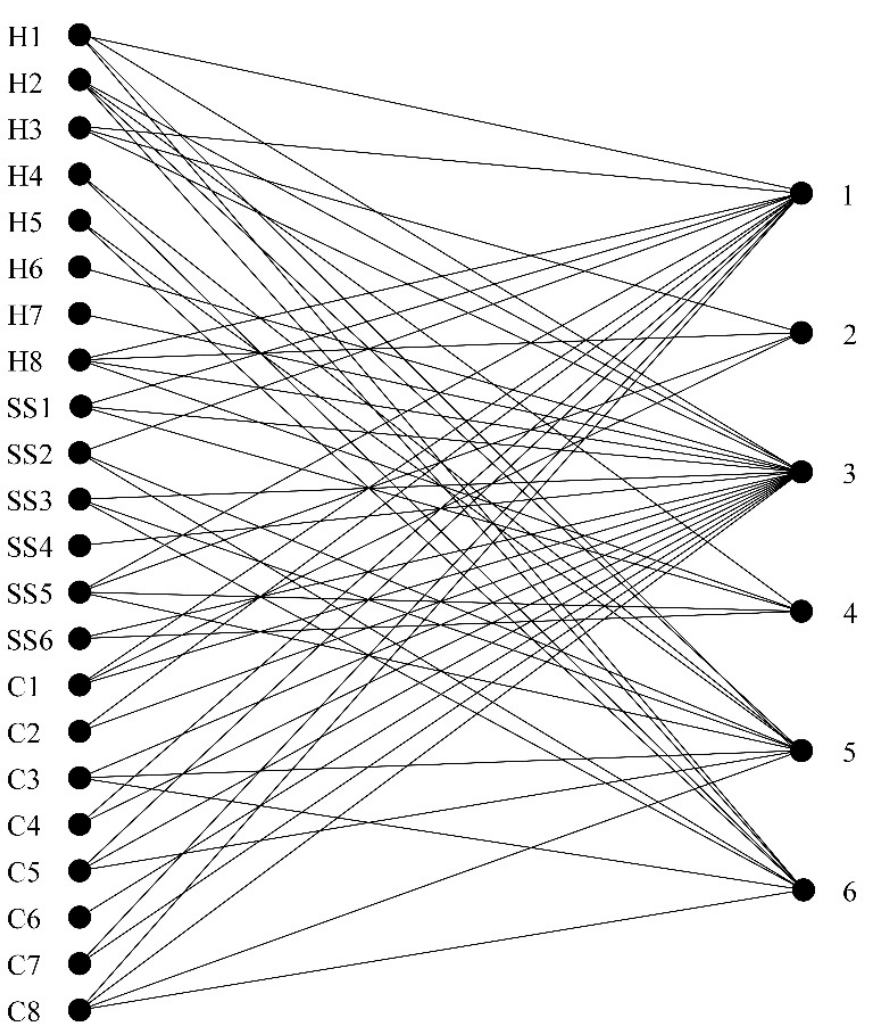

Fig. 3 Bipartite network of social sustainability indicators and stakeholders

impact that indicator has on each other, what further allows determination of the indicators that are most important for the assessment. The advantage of using this method is reflected in its ability to obtain the results for prioritization of the indicators even when the data for the calculation of the indicators is not available. It is because bipartite network projections relays on the relation between the nodes. Thus it is not directly related to the calculated values of the indicators after using proposed formulas from Section 2. However, the results obtained from bipartite network projection (Table A2) cannot be used to measure the performance of the wastewater treatment plant.

The collection of data for the indicators' calculation can be time-consuming and expensive. Therefore the main purpose of bipartite network projection is prioritization of the indicators for the purpose of cost optimization. Also if it is known that personal perceptions can have significant influence on the process of choosing the indicators for the assessment [39], bipartite network projection can help in avoiding that subjectivity.

\section{Conclusions}

Quality of life, and its specific subcategories: health, safety and security, and comfort, were selected as key themes for the identification and development of social sustainability indicators for a wastewater treatment process, as well as for identification of the interdependencies of the indicators. The main novelty of this 
paper consists in proposing social sustainability criteria specific to wastewater treatment processes, the formulation of indicators enabling their quantitative assessment, the creation of a network of their dependence with stakeholders, as well as determination of the impact of each indicator. The goal of the identified and developed indicators is to provide a more comprehensive definition of social sustainability and to enable the use of a quantitative approach to social sustainability evaluation.

Example of the use of the indicators in evaluation of wastewater treatment plant processes are presented for North Toronto Wastewater Treatment Plant. The aim of applying the indicators to the wastewater treatment plant was to show how social sustainability might be assessed in a quantitative way and to determine to what extent can it be applied to assessment of a wastewater treatment plant.

The approach demonstrated the feasibility of applying the social indicators introduced in this study to wastewater treatment. The presented approach allows periodical monitoring (annually) of wastewater treatment plant operations.

It should be noted that this paper does not limit evaluation of social sustainability of wastewater treatment plants just to the indicators presented in this study. Especially, as social sustainability is a broad concept and its assessment can be influenced by cultural preferences, experience, personal perceptions, etc.

The lack of availability of some data required for evaluation of some indicators may be due to the high costs of getting information. The approach used in this research for weighting the network can assist in cost optimization. By prioritizing the indicators on the basis of their impact (Table A2 - orange values) it is possible to see which indicators are absolutely essential for evaluation of social sustainability. Data acquisition costs can be reduced by obviating the need to evaluate all indicators.

The results of the ranking are not obtained on the basis of the direct preferences of the stakeholders but are found thanks to analysis of the complex network of links between the stakeholders and indicators. Thus it can help to avoid subjectivity in ranking the indicators.

The proposed method for analysis of a set of indicators can be used in a broad range of industries. Every industry has different stakeholders and specific sets of indicators with specific connections to stakeholders. The connections can result from the different priorities expressed by the various stakeholders. The proposed method can help rank the indicators for a given industry, and the ranking could lead to determination of a set of the most essential social indicators for a given industry. Such a "critical set of indicators" may differ for different industries due to the varying topology of the complex network of stakeholders and indicators. Further detailed analysis is required to assess the precise characteristics of the networks of various industries.

Because of the complexity of the concept of social sustainability, the future research should address the issue of its quantification using fuzzy numbers or probability distribution.

\section{Acknowledgement}

Financial support to Tamara Popovic from the Graduate School in Chemical Engineering (GSCE), Finland is gratefully acknowledged. The authors would like to thank Peter Jones for his support in editing and structuring this manuscript. The authors would like to thank anonymous reviewers whose comments, questions and suggestions helped to improve the quality of this paper.

\section{References}

[1] Muga, H. E., Mihelcic, J. R. "Sustainability of wastewater treatment technologies." Journal of Environmental Management. 88(3), pp. 437-447. 2008.

https://doi.org/10.1016/j.jenvman.2007.03.008

[2] Palme, U., Lundin, M., Tillman, A. M., Molander, S. "Sustainable development indicators for wastewater systems - researchers and indicator users in a co-operative case study." Resources, Conservation and Recycling. 43(3), pp. 293-311. 2005.

https://doi.org/10.1016/j.resconrec.2004.06.006

[3] Marques, R. C., da Cruz, N. F., Pires, J. "Measuring the sustainability of urban water services." Environmental Science \& Policy. 54, pp. 142-151. 2015.

https://doi.org/10.1016/j.envsci.2015.07.003

[4] Munier, N. "Measuring sustainability." In: Munier, N. (ed.), Introduction to Sustainability - Road to a Better Future. Springer, Netherlands, (pp. 265-314). 2005.

[5] Balkema, A. J., Preisig, H. A., Otterpohl, R., Lambert, F. J. D. "Indicators for the sustainability assessment of wastewater treatment systems." Urban Water. 4(2), pp. 153-161. 2002. https://doi.org/10.1016/S1462-0758(02)00014-6

[6] Molinos-Senante, M., Gómez, T., Garrido-Baserba, M., Caballero, R., Sala-Garrido, R. "Assessing the sustainability of small wastewater treatment system: A composite indicator approach." Science of the Total Environment. 497-498, pp. 607-617. 2014 https://doi.org/10.1016/j.scitotenv.2014.08.026

[7] Padilla-Rivera, A., Morgan-Sagastume, J. M., Noyola, A., Güereca, L. P. "Addressing social aspects associated with wastewater treatment facilities." Environmental Impact Assessment Review. 57, pp. 101-113. 2016. https://doi.org/10.1016/j.eiar.2015.11.007

[8] Veldhuizen, L. J. L., Berentsen, P. B. M., Bokkers, E. A. M., de Boer, I. J. M. "Social sustainability of cod and haddock fisheries in the northeast Atlantic: what issues are important?." Journal of Cleaner Production. 94, pp. 76-85. 2015. https://doi.org/10.1016/j.jclepro.2015.01.078

[9] Dreyer, L. C., Hauschild, M. Z., Schierbeck, J. "A framework for social life cycle impact assessment." The International Journal of Life Cycle Assessment. 11(2), pp. 88-97. 2006. https://doi.org/10.1065/lca2005.08.223

[10] GRI (Global Reporting Initiative) "G4 Sustainability reporting guidelines." Reporting principles and standard disclosures. 2013. [Online]. Available from: https://www.globalreporting.org/standards/Pages/default.aspx. [Accessed: 8th August 2015].

[11] Rahdari, A. H., Anvary Rostamy, A. A. "Designing a general set of sustainability indicators at the corporate level." Journal of Cleaner Production. 108(Part A), pp. 757-771. 2015. https://doi.org/10.1016/j.jclepro.2015.05.108

[12] Bañares-Alcántara, R. "Perspectives on the potential roles of engineers in the formulation, implementation and enforcement of policies." Computers and Chemical Engineering. 34(3), pp. 267-276. 2010. https://doi.org/10.1016/j.compchemeng.2009.10.010 
[13] Naser, A., Kamranim, A. K. "Chapter 1: Introduction to systems engineering." In: Naser, A., Kamranim, A. K. (eds.), Intelligent Transport and Evacuation Planning: A Modelling-Based Approach. Springer, Netherlands, (pp. 1-15). 2012.

[14] United Nations "Indicators of sustainable development: Guidelines and methodologies." New York: United Nations. 2007. [Online]. Available from: http://www.un.org/esa/sustdev/natlinfo/indicators/guidelines.pdf. [Accessed: 12th August 2015].

[15] Littig, B., Grießler, E. "Social sustainability: a catchword between political pragmatism and social theory." International Journal of Sustainable Development (IJSD). 8(1-2), pp. 65-79. 2005. https://doi.org/10.1504/IJSD.2005.007375

[16] Mitchell, G., May, A., McDonald, A. "PICABUE: a methodological framework for the development of indicators of sustainable development." International Journal of Sustainable Development \& World Ecology. 2, pp. 104-123. 1995. https://doi.org/10.1080/13504509509469893

[17] Mitchell, G. "Problems and fundamentals of sustainable development indicators." Sustainable Development. 4(1), pp. 1-11. 1996. https://doi. org/10.1002/(SICI)1099-1719(199603)4:1<1::AID-SD24>3.0.CO;2-N

[18] U.S. EPA "Report to congress: clean water needs survey." Office of wastewater management. 2008. [Online]. Available from: https://www.epa. gov/cwns/clean-watersheds-needs-survey-cwns-report-congress-2008. [Accessed: 9th January 2017].

[19] Annual report North Toronto Wastewater Treatment Plant. 2010. [Online]. Available from: http://www1.toronto.ca/wps/portal/contento nly?vgnextoid $=$ da8807 ceb6f8e310 VgnVCM10000071d60f89RCRD\& vgnextchannel $=0 \mathrm{db} 7 \mathrm{f} 75 \mathrm{e} 4 \mathrm{f} 18 \mathrm{f} 310 \mathrm{VgnVCM} 10000071 \mathrm{~d} 60$ f89RCRD. [Accessed: 12th August 2015].

[20] Yin, F., Zhao, X., Zhang, X., Ge, B., Xiao, W. "Improving accuracy and scalability of personal recommendation based on bipartite network projection." Mathematical Problems in Engineering. 2014, Article ID 823749, pp. 1-11. 2014. https://doi.org/10.1155/2014/823749

[21] Zhang, D., Dai, M., Li, L., Zhang, C. "Distribution characteristics of weighted bipartite evolving networks." Physica A: Statistical Mechanism and its Applications. 428, pp. 340-350. 2015. https://doi.org/10.1016/j.physa.2015.02.010

[22] Zhou, T., Ren, J., Medo, M., Zhang, Y.-C. "Bipartite network projection and personal recommendation." Physical Review E. 76(4), pp. 1-7. 2007. https://doi.org/10.1103/PhysRevE.76.046115

[23] Gerdes, L. M. "Dependency centrality from bipartite social networks." Connections. 34(1\&2), pp. 14-29. 2014. https://doi.org/10.17266/34.1.2

[24] Tchobanoglous, G., Burton, F. L., Stensel, H. D., Metcalf \& Eddy "Wastewater Engineering: Treatment and Reuse." 4th ed., McGraw Hill Education, Singapore. 2004.

[25] Popovic, T., Kraslawski, A. "Social sustainability of complex systems." In: You, F. (ed.), Sustainability of Products, Processes and Supply Chains. Theory and Application. Computer-Aided Chemical Engineering 36. Elsevier, USA, (pp. 605-614). 2015.

https://doi.org/10.1016/B978-0-444-63472-6.00024-0

[26] Spellman, F. R. "Handbook of water and wastewater treatment plant operations." 2nd ed., Taylor and Francis Group, Boca Raton, FL. 2009.

[27] EPA "Protocol for conducting environmental compliance audits for municipal facilities under U.S." EPA's wastewater regulations. Enforcement and Compliance Assurance. 2000. [Online]. Available from: http://www. epa.gov/compliance/guidance-protocol-conducting-environmental-compliance-audits-municipal-facilities-under. [Accessed: 5th August 2015].
[28] Johansson, A. C. H., Svedung, I., Andersson, R. "Management of risks in societal planning - an analysis of scope and variety of health, safety and security issues in municipality plan documents." Safety Sciences. 44(8), pp. 675-688. 2006. https://doi.org/10.1016/j.ssci.2006.03.001

[29] Agenda 21 "United Nations Conference on Environment and Development". Rio de Janerio, Brazil. 1992. [Online]. Available from: https://sustainabledevelopment.un.org/content/documents/Agenda21. pdf. [Accessed: 10th September 2015].

[30] Ratna, R., Kaur, T. "Measuring impacts of trade unions of workmen satisfaction in a manufacturing unit." International Journal of Management and Social Sciences Research (IJMSSR). 1(1), pp. 49-54. 2012.

[31] Halme, M., Jasch, C., Scharp, M. "Sustainable homeservices? Toward household services that enhance ecological, social and economic sustainability." Ecological Economic. 51(1-2), pp. 125-138. 2004. https://doi.org/10.1016/j.ecolecon.2004.04.007

[32] McGinley, M. A. "Quantifying public perception of odors in a community - utilizing telemarketing protocol." In: Air and Waste Management Association International Specialty Conference: Odor and Environmental Air. St. Croix Sensory Inc., North Stillwater, pp. 310-322. 1995.

[33] EPA "Collection systems O\&M fact sheet. Sewer cleaning and inspection." United States Environmental Protection Agency, US. 1999. [Online]. Available from: http://water.epa.gov/scitech/wastetech/upload/2002_06_28_mtb_sewcl.pdf. [Accessed: 20th July 2015].

[34] Annual report North Toronto Wastewater Treatment Plant. 2011. [Online]. Available from: http://www1.toronto.ca/wps/portal/contento nly?vgnextoid=da8807 ceb6f8e310 VgnVCM10000071d60f89RCRD\& vgnextchannel=0 db7f75e4f18f310 VgnVCM10000071 d60f89RCRD. [Accessed: 12th August 2015].

[35] Annual report North Toronto Wastewater Treatment Plant. 2012. [Online]. Available from: http://www1.toronto.ca/wps/portal/contento nly?vgnextoid=da8807ceb6f8e310 VgnVCM10000071d60f89RCRD\& vgnextchannel $=0 \mathrm{db} 7 \mathrm{f} 75 \mathrm{e} 4 \mathrm{f} 18 \mathrm{f} 310 \mathrm{VgnVCM} 10000071 \mathrm{~d} 60 \mathrm{f} 8 \mathrm{RCRD}$. [Accessed: 12th August 2015].

[36] Annual report North Toronto Wastewater Treatment Plant. 2013. [Online]. Available from: http://www1.toronto.ca/wps/portal/contento nly?vgnextoid $=\mathrm{da} 8807 \mathrm{ceb} 6 \mathrm{f} 8 \mathrm{e} 310 \mathrm{VgnVCM} 10000071 \mathrm{~d} 60 \mathrm{f} 89 \mathrm{RCRD} \&$ vgnextchannel $=0 \mathrm{db} 7 \mathrm{f} 75 \mathrm{e} 4 \mathrm{f} 18 \mathrm{f} 310 \mathrm{VgnVCM} 10000071 \mathrm{~d} 60 \mathrm{f} 8 \mathrm{RCRD}$. [Accessed: 12th August 2015].

[37] Annual report North Toronto Wastewater Treatment Plant. 2014. [Online]. Available from: http://www1.toronto.ca/wps/portal/contento nly?vgnextoid $=\mathrm{da} 8807 \mathrm{ceb} 6 \mathrm{f} 8 \mathrm{e} 310 \mathrm{VgnVCM} 10000071 \mathrm{~d} 60 \mathrm{f} 89 \mathrm{RCRD} \&$ vgnextchannel $=0 \mathrm{db} 7 \mathrm{f} 75 \mathrm{e} 4 \mathrm{f} 18 \mathrm{f} 310 \mathrm{VgnVCM} 10000071 \mathrm{~d} 60 \mathrm{f} 8 \mathrm{RCRD}$. [Accessed: 12th August 2015].

[38] United Nations Economic and Social Commission for Asia and the Pacific (ESCAP), United Nations Human Settlements Programme (UN-Habitat) and Asian Institute of Technology (AIT) "Policy Guidance Manual on Wastewater Management with a Special Emphasis on Decentralized Wastewater Treatment Systems." Bangkok. Thailand. 2015.

[39] Bell, S., Morse, S. "Sustainability indicators. Measuring the immeasurable?." 2nd ed., Earthscan, London. 2008. 
Table A1 Weighting of the bipartite network presented in Fig. 3

\begin{tabular}{|c|c|c|c|c|c|c|c|c|c|c|c|c|c|c|c|c|c|c|c|c|c|c|}
\hline & H1 & $\mathrm{H} 2$ & 3 & 14 & H5 & H6 & $\mathrm{H} 7$ & H8 & SS1 & SS2 & SS3 & 54 & SS5 & SS6 & 1 & $\mathrm{C} 2$ & $\mathrm{C} 3$ & 24 & $\mathrm{C} 5$ & C6 & C7 & $\mathrm{C} 8$ \\
\hline 1 & 0.09 & & & & & & 0.06 & & & 0.1 & & 0.06 & & 0.03 & .05 & 7 & 9 & 7 & 08 & 6 & 97 & 09 \\
\hline $\mathrm{H} 2$ & 07 & 12 & 02 & & & 06 & 0.06 & 66 & 99 & $0 .($ & 09 & 0.06 & 0.08 & 3 & .02 & .03 & 99 & .03 & .05 & 06 & .03 & 0.07 \\
\hline $\mathrm{H} 3$ & 0.03 & 0.01 & 0.13 & 0 & 0 & 0. & 0.06 & 0.1 & 5 & 0.03 & 0.02 & 0.06 & 0.08 & 0. & 13 & 97 & 0.02 & 0.07 & .05 & 0.06 & 0.07 & 0.03 \\
\hline $\mathrm{H} 4$ & 0.06 & 0 & , & 01 & & 0 & 0 & 0 & 0 & 008 & 008 & 0 & 003 & . & $n_{1}$ & 0 & 008 & 0 & 0.03 & 0 & 0 & 0.06 \\
\hline H5 & 0.06 & 0.06 & 0 & & & 0 & 0 & 0 & 0 & & 0.08 & 0 & 0. & 0 & 0 & 0 & 0.08 & 0 & 3 & 0 & 0 & 0.06 \\
\hline H6 & 0.01 & 0.01 & 1.0 & 0 & 0 & 0.06 & 0.06 & 0.01 & 0.02 & 0 & 0.02 & 0.06 & 0 & 0. & 0.02 & 0.03 & 0.02 & 0.03 & 0.02 & 0.06 & 0.03 & 0.01 \\
\hline $\mathrm{H} 7$ & 0.01 & 01 & 02 & 0 & 0 & 0.06 & 0.06 & 01 & 0.02 & 0 & 0.02 & 0.06 & 0 & 0.03 & 0.02 & 0.03 & 0.02 & 0.03 & 0.02 & 0.06 & 0.03 & 0.01 \\
\hline H8 & 0.03 & 0.06 & 0.13 & 0 & 0 & 0.0 & 0.06 & 0.15 & 0. & 0. & 00 & 06 & 0 & 0.13 & 0.13 & 97 & 0 . & 0.07 & 0.05 & 0.06 & .07 & 0.03 \\
\hline SS1 & 33 & 0.06 & 0.05 & 0 & 0 & 0.06 & 0.06 & 0.00 & 0.11 & 0.03 & 0.02 & 6 & 0.07 & 0.13 & .05 & 0.07 & 0.02 & 0.07 & 05 & 0.06 & 7 & 0.03 \\
\hline SS2 & 0.08 & .06 & .03 & 0. & 0.11 & 0 & 0 & 0.02 & 0.03 & 0. & 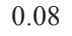 & 0 & 0. & 0 & 0.03 & 0.04 & 0. & 0.04 & 0.06 & 0 & 0.04 & 0.08 \\
\hline SS3 & 0.07 & 0.07 & 0.02 & 0.1 & 0.1 & 0.06 & 0.06 & 0.01 & 0.02 & 0.0 & 0.09 & 0.06 & 0.03 & 0.03 & 0.02 & 0.03 & 0.09 & 0.03 & 0.05 & 0.06 & 0.03 & 0.07 \\
\hline SS4 & 0.01 & 0.01 & 02 & 0 & 0 & 0. & 0. & 0.01 & 0 & 0 & 0.02 & 0. & 0 & 0.03 & 0.02 & 3 & 2 & 0.03 & 12 & 0.06 & 03 & .01 \\
\hline SS5 & (1) & 0.08 & 0.11 & 0.05 & & 0 & 0 & 012 & 0 & 0. & 0.03 & 0 & 0. & 0. & 0.1 & 0. & 0 . & 0.0 & 0.00 & 0 & 0.04 & 0.05 \\
\hline SS6 & 0.01 & 0.06 & .02 & 0 & 0 & 0.06 & 0.06 & 0.06 & 0.09 & 0 & 0.0 & 0.06 & 0.05 & 0.1 & 0.02 & 0.03 & 0.0 & 0.03 & 0.02 & 0. & 0.03 & 0.01 \\
\hline $\mathrm{C} 1$ & 0.03 & 0.01 & 0.13 & 0 & 0 & 0.06 & 0.06 & 0.1 & 0.05 & 0.0 & 0.02 & 0.06 & 0.08 & 0.03 & 0.13 & 0.07 & 0.02 & 0.07 & 0.05 & 0.06 & 0.07 & 0.03 \\
\hline C2 & 0.03 & 0.01 & 0.05 & 0 & 0 & 0.06 & 0.06 & 0.03 & 0.05 & 0.03 & 0.02 & 0.06 & 0.02 & 0.03 & 0.05 & 0.07 & 0.02 & 0.07 & 0.05 & 0.06 & 0.07 & 0.03 \\
\hline C3 & 0.01 & 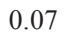 & 02 & 0 & & $0.0 c$ & 00 & 0.01 & 0. & 0 & 0.6 & 0. & 0.03 & 0. & 0.02 & 0 & 0 & 0.0 & 0.05 & 0.06 & 0.03 & 0.07 \\
\hline C4 & 0.03 & 0.01 & 0.05 & 0 & 0 & 0.06 & 0.06 & 0.03 & 0.05 & 0.03 & 0.02 & 0.06 & 0.02 & 0.03 & 0.05 & 0.07 & 0.02 & 0.07 & 0.05 & 0.06 & 0.07 & 0.03 \\
\hline $\mathrm{C} 5$ & 0.06 & 0.04 & 0.05 & 0.0 & 0.0 & 0.06 & 0.06 & 0.03 & 0.05 & 0.06 & 0.05 & 0.06 & 0.05 & 0.03 & 0.05 & 0.07 & 0.05 & 0.07 & 0.08 & 0.06 & 0.07 & 0.06 \\
\hline C6 & 0.01 & 0.01 & 0.02 & 0 & 0 & 0.06 & 0.06 & 0.0 & 0.02 & 0 & 0.0 & 0.06 & 0 & 0. & 0.02 & 0.03 & 0.02 & 0.03 & 0.02 & 0 & 0.03 & 0.01 \\
\hline C7 & 0.03 & 0.01 & 0.05 & 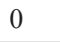 & 0 & 0.06 & 006 & 00 & 0.05 & 0.0 & 00 & 0.06 & 0 & 0.0 & 005 & 0.07 & 0.02 & 0.07 & 0.05 & 0.06 & 0.07 & 0.03 \\
\hline C8 & 0.09 & 0.07 & 0.05 & 0.11 & 0.11 & 0.06 & 0.06 & 0.03 & 0.05 & 0.1 & 0.09 & 0.06 & 0.05 & 0.03 & 0.05 & 0.07 & 0.09 & 0.07 & 0.08 & 0.06 & 0.07 & 0.09 \\
\hline
\end{tabular}

Table A2 Pair-wise dependencies among indicators

\begin{tabular}{|c|c|c|c|c|c|c|c|c|c|c|c|c|c|c|c|c|c|c|c|c|c|c|}
\hline & H1 & $\mathrm{H} 2$ & H3 & $\mathrm{H} 4$ & H5 & H6 & $\mathrm{H} 7$ & $\mathrm{H} 8$ & SS1 & $\mathrm{SS} 2$ & SS3 & SS4 & SS5 & SS6 & $\mathrm{C} 1$ & $\mathrm{C} 2$ & $\mathrm{C} 3$ & $\mathrm{C} 4$ & $\mathrm{C} 5$ & C6 & C7 & $\mathrm{C} 8$ \\
\hline H1 & 0 & 7 & 8 & 0.62 & .62 & 5 & 0.15 & 0.38 & 8 & 0.85 & .77 & 15 & 0.50 & .15 & 38 & 0.38 & 0.77 & 0.38 & 0.66 & 0.15 & 0.38 & 1 \\
\hline $\mathrm{H} 2$ & 0.58 & 0 & 0.12 & 0.47 & 0.47 & 0.12 & 0.12 & 0.53 & 0.53 & 0.47 & 0.58 & 0.12 & 0.62 & 0.53 & 0.12 & 0.12 & 0.58 & 0.11 & 0.32 & 0.15 & 0.38 & 0.58 \\
\hline $\mathrm{H} 3$ & 0.36 & 0.14 & 0 & 0 & 0 & 0.14 & 0.14 & 1 & 0.36 & 0.21 & 0.14 & 0.14 & 0.86 & 0.14 & 1 & 0.38 & 0.14 & 0.36 & 0.36 & 0.14 & 0.36 & 0.36 \\
\hline $\mathrm{H} 4$ & 1 & 1 & 0 & 0 & 1 & 0 & 0 & 0 & 0 & 1 & 1 & 0 & 0.44 & 0 & 0 & 0 & 1 & 0 & 0.44 & 0 & 0 & 1 \\
\hline H5 & 1 & 1 & 0 & 1 & 0 & 0 & 0 & 0 & 0 & 1 & 1 & 0 & 0.44 & 0 & 0 & 0 & 1 & 0 & 0.44 & 0 & 0 & 1 \\
\hline H6 & 1 & 1 & 11 & 0 & 0 & 0 & 1 & 1 & 1 & 0 & 1 & 1 & 0 & 1 & 1 & 1 & 1 & 1 & 1 & 1 & 1 & 1 \\
\hline $\mathrm{H} 7$ & 1 & 1 & 1 & 0 & 0 & 1 & 0 & 1 & 1 & 0 & . & 1 & 0 & 1 & 1 & 1 & 1 & 1 & 1 & 1 & 1 & 1 \\
\hline H8 & 0.2 & 0 . & 0.6 & 0 & 0 & 0. & 1 & 0 & 0 . & 0.14 & 0.09 & 0.09 & 0.91 & 0.43 & 0.66 & 0.24 & 0.09 & 0.24 & 0.24 & 0.09 & 0.24 & 0.24 \\
\hline SS1 & 0.41 & 0.75 & 0.41 & 0 & 0 & 0.16 & 0.16 & 1 & 0 & 0.25 & 0.16 & 0.16 & 0.84 & 0.75 & 0.41 & 0.41 & 0.16 & 0.41 & 0.41 & 0.16 & 0.41 & 0.41 \\
\hline SS2 & 1 & 0.73 & 0.27 & 0.73 & 0.73 & 0 & 0 & 0.27 & 0.27 & 0 & 0.73 & 0 & 0.59 & 0 & 0.27 & 0.27 & 0.73 & 0.27 & 0.59 & 0 & 0.27 & 1 \\
\hline SS3 & 1 & 1 & 0.2 & 0.80 & 0.80 & 0.20 & 0.20 & 0.20 & 0.20 & 0.80 & 0 & 0.20 & 0.36 & 0.20 & 0.20 & 0.20 & 1 & 0.20 & 0.55 & 0.20 & 0.20 & 1 \\
\hline SS4 & 1 & 1 & 1 & 0 & 0 & 1 & 1 & 1 & 1 & 0 & 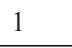 & 0 & 0 & 1 & 1 & 1 & 1 & 1 & 1 & 1 & 1 & 1 \\
\hline SS5 & 0.2 & 0. & 0.5 & 0.1 & 0.16 & 0 & 0 & 0.8 & 0.45 & 0.2 & 0.1 & 0 & 0 & 0.32 & 0.53 & 0.13 & 0.16 & 0.13 & 0.29 & 0 & 0.13 & 0.29 \\
\hline SS6 & 0.22 & 1 & 0.2 & 0 & 0 & 0.2 & 0.22 & 1 & 1 & 0 & 0.22 & 0.22 & 0.78 & 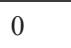 & 0.22 & 0.22 & 0.22 & 0.22 & 0.22 & 0.21 & 0.22 & 0.22 \\
\hline $\mathrm{C} 1$ & 0.36 & 1 & 1 & 0 & 0 & 0.14 & 0.14 & 1 & 0.36 & 0.21 & 0.14 & 0.14 & 0.86 & 0.14 & 0 & 0.36 & 0.14 & 0.36 & 0.36 & 0.14 & 0.36 & 0.36 \\
\hline $\mathrm{C} 2$ & 1 & 0.4 & 1 & 0 & 0 & 0.4 & 0.40 & 1 & 1 & 0.60 & 0.40 & 0.4 & 0.6 & 0.40 & 1 & 0 & 0.4 & 1 & 1 & 0.4 & 1 & 1 \\
\hline $\mathrm{C} 3$ & 1 & 1 & 0.2 & 0.80 & 0.80 & 0.20 & 0.20 & 0.20 & 0.20 & 0.80 & 1 & 0.20 & 0.36 & 0.20 & 0.20 & 0.20 & 0 & 0.20 & 0.55 & 0.20 & 0.20 & 1 \\
\hline $\mathrm{C} 4$ & 1 & 0.4 & 1 & 0 & 0 & 0.40 & 0.40 & 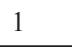 & 1 & 0.60 & 0.40 & 0.4 & 0.6 & 0.40 & 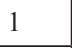 & 1 & 0.4 & 0 & 1 & 0.4 & 1 & 1 \\
\hline C5 & 1 & 0.65 & 0.58 & 0.42 & 0.42 & 0.23 & 0.23 & 0.58 & 0.58 & 0.77 & 0.65 & 0.23 & 0.77 & 0.23 & 0.58 & 0.58 & 0.65 & 0.58 & 0 & 0.23 & 0.58 & 1 \\
\hline $\mathrm{C} 6$ & 1 & 1 & 1 & 0 & 0 & 1 & 1 & 1 & 1 & 0 & 1 & 1 & 0 & 1 & 1 & 1 & 1 & 1 & 1 & 0 & 1 & 1 \\
\hline $\mathrm{C} 7$ & 1 & 0.4 & 1 & 0 & 0 & 0.40 & 0.40 & 1 & 1 & 0.60 & 0.40 & 0.40 & 0.6 & 0.40 & 1 & 1 & 0.4 & 1 & 1 & 0.4 & 0 & 1 \\
\hline $\mathrm{C} 8$ & 1 & 0.77 & 0.38 & 0.62 & 0.62 & 0.15 & 0.15 & 0.38 & 0.38 & 0.85 & 0.77 & 0.15 & 0.50 & 0.15 & 0.38 & 0.38 & 0.77 & 0.38 & 0.66 & 0.15 & 0.38 & 0 \\
\hline Score & 0.78 & 0.76 & 0.57 & 0.27 & 0.27 & 0.29 & 0.33 & 0.68 & 0.58 & 0.45 & 0.60 & 0.29 & 0.51 & 0.40 & 0.57 & 0.47 & 0.60 & 0.47 & 0.62 & 0.29 & 0.48 & 0.78 \\
\hline
\end{tabular}

